\title{
THEORIZING IN SOCIAL SCIENCE: THE CONTEXT OF DISCOVERY BY RICHARD SWEDBERG (STANFORD, STANFORD UNIVERSITY PRESS, 2014)
}

\author{
ÁDÁM KORNÉL HAVAS, SEDEN SAFAK EREN, SZIDÓNIA KATALIN \\ NAGY, GARGI ROY, MOUNIA UTZERI AND ALI WAZIRI
}

Richard Swedberg, well known for his work in economic sociology ${ }^{2}$ and one of the doyens of the rising movement in analytical sociology ${ }^{3}$, offers the reader a pessimistic view of the current state-of-the-art about sociological theorizing. Indeed, compared to empirical methods or other sciences such as cognitive science, sociological theory has advanced little over the last decades. The prognosis is simple: students and researchers are taught theories but cannot theorize. If this is the case, then what is to be done? What does 'theorizing' mean exactly?

In an earlier publication, The Art of Social Theory ${ }^{4}$, Swedberg attempted to provide an overview of the state of theorising in social sciences and offered practical tips and techniques for initiating theorizing. Here he strikes a second time and deepens the investigation of the topic with the ambitious Theorizing in Social Science, the Context of Discovery. The book, as the subtitle explicitly indicates, focuses on the context in which creativity is primarily what matters when a theory is devised. Grounding his argument upon the work of the forefathers of sociology such as Weber, Popper, and Durkheim, Swedberg punctures the myth of logical and rational thinking, arguing that the process of theorising is imperfect, and in which creativity, inspiration and intuition play a

\footnotetext{
1 The book reviewers are currently enrolled in the Ph.D. program at the Department of Sociology, Corvinus University, Budapest, Hungary. Group contact: wababer@gmail.com

2 Granovetter, M., \& Swedberg, R. (2011), “The Sociology of Economic Life”, 3rd edition. Boulder, CO. Westview Press.

3 Hedström, P., \& Swedberg, R. (1998), "Social mechanisms: An analytical approach to social theory". Cambridge University Press.

4 Swedberg, R. (2014), “The Art of Social Theory”. Princeton University Press.
} 
significant role. This proposition is rather unusual in the world of social science. At this point, we may all ask: 'Well then, how shall we theorise?' The answer is the strength of Theorising in Social Science, as the volume suggests not one single approach, but proposes various pathways for the different disciplines of social sciences, as briefly discussed further. Supported by an eclectic cohort of eminent researchers from diverse fields of sociology, such as sociology of knowledge, sociology of organisation and economic sociology, the goal of the monograph is to suggest potential ways of going beyond sometimes rigidly defined academic frameworks towards more flexible and adaptive theorizing that is open to new perspectives.

The book is divided into nine chapters, in which each contributor describes their own set of tools for unpacking the process of theorising. Swedberg's first chapter lays the ground for dissecting the very process of thinking while researching social phenomena. The author draws an analytical distinction between the two phases of scientific research; namely, between pre-study, in which creative, unorthodox ways of observing a social phenomenon are allowed, and main study, characterised by rigorous empirical justification. 'Intuitionist theorizing', written by Karin Knorr Cetina, an Austrian sociologist active in the fields of sociology of knowledge and economic sociology, problematizes the role of intuition in the complicated process of (social) scientific inquiry. Examples from the author's earlier research illustrate that intuition is not the antonym of rational thinking; rather, it is a system of information processing which operates on an unconscious basis. Integrating the findings of neuroand psychological literature, the author suggests that the rise in awareness of the interplay between adequate theorizing and intuitional theorizing implies a shift from bureaucratic scientific activity to more flexible work; one which allows room for the creativity necessary to advance science.

Diane Vaughan, a sociologist of organisations who has worked on analogical theorizing for decades, argues for the need to develop theory from qualitative data based on cross-case analysis. Drawing on her own research into organizations, she argues that comparing similar events, activities or phenomena across different organizational forms can help with the elaboration of general theory or concepts. The structure of her main thesis is adopted by Reed and Zald, who pinpoint the collective and embedded dimensions of theorizing by taking 'communities of inquiry' (networks of researchers), as the basic unit of analysis. First, the construction of theory is not solely an individual activity. Second, internal (individual) and external (social) forces shape in many complex ways the process of theory building. According to the authors, because social science is rooted in the "civilizational" context, theorizing social science is nothing more than social theorizing. Accordingly, the authors call for self-reflexivity 
by emphasizing the social and civilizational embeddedness of the theorizing of social science. Considering this, the authors propose the formulation of a model of theory development in communities of inquiry (i.e. collectively) that includes variations, and "different pathways" (p. 93) and which allows for more flexibility.

The fifth chapter instead offers a rather pragmatic tool for assessing and screening what is often and cursorily called "theory", but which is in fact a model, especially in the field of economics. Klein's threefold question recentres the debate around how to handle theory and make sure that we theorize well. Stephen Turner in the sixth chapter distinguishes between three forms of theorizing; namely, (1) mundane theorizing, and (2) bricolage - which are the starting points for - (3) developing ideas. Neither mundane theorizing nor bricolage demands the highest level of creativity. Bildung, the most creative and advanced form of theorizing, creates new ideas. It understands established ideas and comes up with something fresh, often challenging accepted theories. Paulsen's seventh chapter discusses the heuristics-based counterfactual imagination as a useful instrument of theory construction. These approaches are mostly ignored by established sociology because of their non-scientific methods. They can, however, be seen as empirically grounded tools because they follow regular patterns and have a rationality of their own. As a result, some stages of counterfactual imagination may be of some importance in helping the theorybuilding process.

$\mathrm{K}$. Weick views theorizing - earlier described as a process that causes one to "rack ones brain" - as a complex and difficult activity for scientists. The effortful "anguish of the theorist" can be grasped in dualities such as variation and retention, living forward while understanding backward, perception and conception, concreteness and abstraction. Through these pairs the process of theorizing can be broken down and become more explicit. In the last chapter, J. March calls for more interpretation in social science instead of only seeking to understand social life. The technological improvements of the last decades have enabled scientists to dissect and search for the mechanisms which explain behaviours. To better interpret life and generate valid social theories, art and its elements ought not be neglected. For this reason, the author argues for the development of a technology of interpretation. How? By paying attention to the role of ambiguity in purposive action, the role of contradictions in intelligence, the role of context in meaning, and the role of affirmation in construction.

With Theorizing in Social Science, Swedberg not only manages to describe and summarise the wide range of currently existing innovative methods and techniques for understanding and uncovering the context of discovery, but 
weaves the contributions (which all strive to change 'mainstream' thinking about how theory building is carried out) together through reference to a common goal, making this volume a coherent corpus of work. This is an ambitious and vibrant project as it concludes that the researcher's - and thus the theorist's - education must be changed in a more flexible, less bureaucratic direction. Swedberg's project simply calls for the democratisation of the activity of theorizing, claiming that theorising is no longer the property of a few talented scientists. In this, Swedberg quotes Kant: "Everyone who can think can ultimately also theorize; and the project of theorizing is inherently democratic" (page 27).

Despite the successes of the volume, certain limitations and concerns arise as to the viability and feasibility of such a project in the current academic and scientific environment. The present authors fully understand and agree with the demand the book contributors make for the importance of intuitionist inspiration, counterfactual imagination, multiple analogies, and the dissolution of the boundaries between interpretation and observation (and so forth) when elaborating theoretical accounts. The contexts of discovery and justification are not so clear-cut, and are iterative by nature. However, the major question that still arises, no matter how passionate and committed the social scientist, is the following: "How can I incorporate and implement the techniques specified in this volume, notwithstanding the actual social structure of American and/or European sociology?" Social Sciences and the humanities are characterised by a trend to ever-increasing sub-specialisation that inevitably leads to the fragmentation of knowledge and practice. Swedberg's book by no means delivers a straightforward answer to these crucial questions - but it has enough merit to spur the required discussion and debate, be this at the collective level of scientific inquiry, or at the individual level of the social scientist. For all these reasons, the authors of this review recommend the monograph to social scientists (and not 'only' to sociologists) from various fields - both qualitative and quantitative - who are consciously seeking to improve their theory-building practices by (self)-reflecting on the pre-existing institutional and academic constraints that channel and shape the theory construction of a fragmented scientific community. 